\title{
Evidence based synthesis for prevention of noninvasive ventilation related facial pressure ulcers
}

\author{
Jaber S. Alqahtani, MSc, BSRC, Mohammed D. AlAhmari, PhD, FAARC.
}

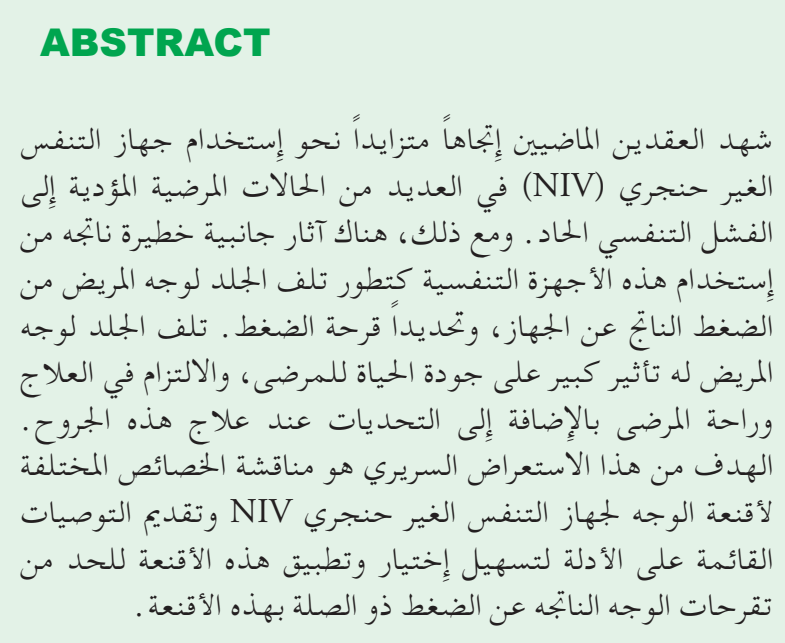

The last 2 decades have seen a growing trend towards the use of noninvasive ventilation (NIV) therapy in the management of many conditions that cause acute respiratory failure. However, there is a serious side effect that results in using these devices; the development of facial skin pressure damage, specifically pressure ulcers. This skin damage has a considerable effect on patients' quality of life, treatment adherence and patients' comfort in addition to the therapy challenges of wound care. The aim of this clinical review is to discuss the different characteristics of NIV interfaces and to provide evidence based recommendations to facilitate the selection and application of such interfaces to reduce NIV interfaces related pressure ulcers.

Saudi Med J 2018; Vol. 39 (5): 443-452 doi: 10.15537/smj.2018.5.22058

From the Respiratory Care Department, Prince Sultan Military College of Health Sciences, Dhahran, Kingdom of Saudi Arabia.

Address correspondence and reprint request to: Dr. Jaber S. Alqahtani, Department of Respiratory Care, Prince Sultan Military College of Health Sciences, Dammam, Kingdom of Saudi Arabia. E-mail:Jaber@psmchs.edu.sa

ORCID ID: orcid.org/0000-0003-1795-5092
7 he use of noninvasive ventilation (NIV) devices has 1 increased steadily in the last 2 decades to become the first line of therapy for various conditions that cause acute respiratory failure. ${ }^{1}$ These devices are currently applied in intensive care units (ICUs), emergency department, stepdown areas, respiratory ward areas, and prehospital settings at home. ${ }^{2-6}$ Noninvasive ventilation refers to the delivery of regular positive pressure support to the patient through a mask, without invasive endotracheal intubation. ${ }^{7}$ This device can efficiently and non-invasively support patients in acute respiratory failure. It helps patients avoid morbidities such as prolonged sedation, ventilator-associated pneumonia, ventilator-induced pulmonary injury, and ventilator dependence and mortality caused by invasive mechanical ventilation, and it ultimately reduces the cost and number of ICU admissions. ${ }^{8-10}$ Despite the overall success of NIV, the failure rate still fluctuates between 18 and $40 \%$. This is attributed to 2 factors: the first factor is a failure to understand the optimal NIV technique necessary to control respiratory failure which includes both the choice of NIV modality and the skills required to use it. The second factor is an increase of respiratory failure despite the use of an optimal NIV technique. ${ }^{1,2,11,12}$ Noninvasive ventilation success depends on several issues, including patient selection, pathology changes, NIV expertise, and patient tolerance to NIV.

Noninvasive ventilation use is associated with devicerelated development of pressure injuries, which is a serious side effect specifically related to the interface. ${ }^{13-15}$ Pressure injuries develop on bony prominence regions due to contact pressure between the interface and the patient's skin. ${ }^{16}$ Pressure injuries have been described by the European Pressure Ulcer Advisory Panel (2014) as a damage to the skin or its underlying tissue that limited to a small area, commonly over a bony prominence. Such a damage results of excessive pressure or pressure load in combination with shear. Pressure injury severity has been classified into 4 types: Type I is the occurrence of non-blanching erythema; Type II is partial thickness 
skin loss; Type III is full-thickness skin loss; and Type IV is full-thickness tissue loss. ${ }^{17}$ The published incidence rate of facial skin breakdown within the literature is between 5 and $50 \% .{ }^{18}$ The treatment and management of pressure injuries are costly; the estimated cost ranges from $£ 1.4$ to $£ 2.1$ billion annually, which is $4 \%$ of the total National Health Service (NHS) expenditure. ${ }^{19,20}$ However, development of these injuries is generally preventable. According to Beitz et al, ${ }^{21}$ pressure injuries can be prevented when health care practitioners are fully aware, educated, and knowledgeable about injury prevention guidelines. Furthermore, hospitals are required to have appropriate NIV devices available for use so that the practitioners can select the optimal ventilation technique with different patients' conditions.

An international survey of NIV use determined that approximately $42 \%$ of patients had failed NIV due to poor patient compliance with the interface and related complications. ${ }^{22}$ Development of facial pressure injuries related to the NIV interface is widely reported in the literature; however, limited data are available on the risk factors and prevention methods that reduce such complications. This affects the recognition of this problem by health care staff, patients, and health care management, and ultimately impacts the patient's quality of life. The purpose of this review is to provide a synthesis based on available evidence to anticipate, avert, and troubleshoot pressure injuries related to NIV interfaces.

Review methods. We searched the Medline, Web of Science, and Cochrane Library electronic databases for evidence published between June 1990 and October 2017; 47 papers were retrieved. An advanced search was conducted using the following key words or Medical Subject Headings (MeSH): "noninvasive ventilation/ AE," "masks," "oronasal mask," "total face mask," "helmet," pressure ulcer/etiology (ET)/prevention and control (PC)," "skin breakdown," "skin compromise," and "skin damage." These terms were combined using the "AND" and "OR" functions to increase the accuracy of the search (Table 1). The reference lists of the selected articles were also searched. The search was limited to published randomized controlled trials (RCTs), observational and case reports of humans, and clinical studies performed in adults written in English. Studies of pediatric cases or children with a lack of comparison or NIV complications were excluded. After screening the papers, 39 studies were rejected. The 9 papers selected included RCTs, prospective cohort studies, a before-after comparison study, a case report, and a cross-sectional study. The rejected papers were letters, responses, non-primary sources, and duplicated
Table 1 - Database search and "hits"

\begin{tabular}{lcc}
\hline Database & $\begin{array}{c}\text { Number of hits } \\
\text { after combining } \\
\text { MESH using } \\
\text { Boolean operators }\end{array}$ & $\begin{array}{c}\text { Number of articles } \\
\text { after abstracts } \\
\text { screening }\end{array}$ \\
\hline MEDLINE & 23 & 3 \\
Web of Science & 13 & 2 \\
Cochrane Library & 12 & 4 \\
Total & 47 & 9 \\
\hline
\end{tabular}

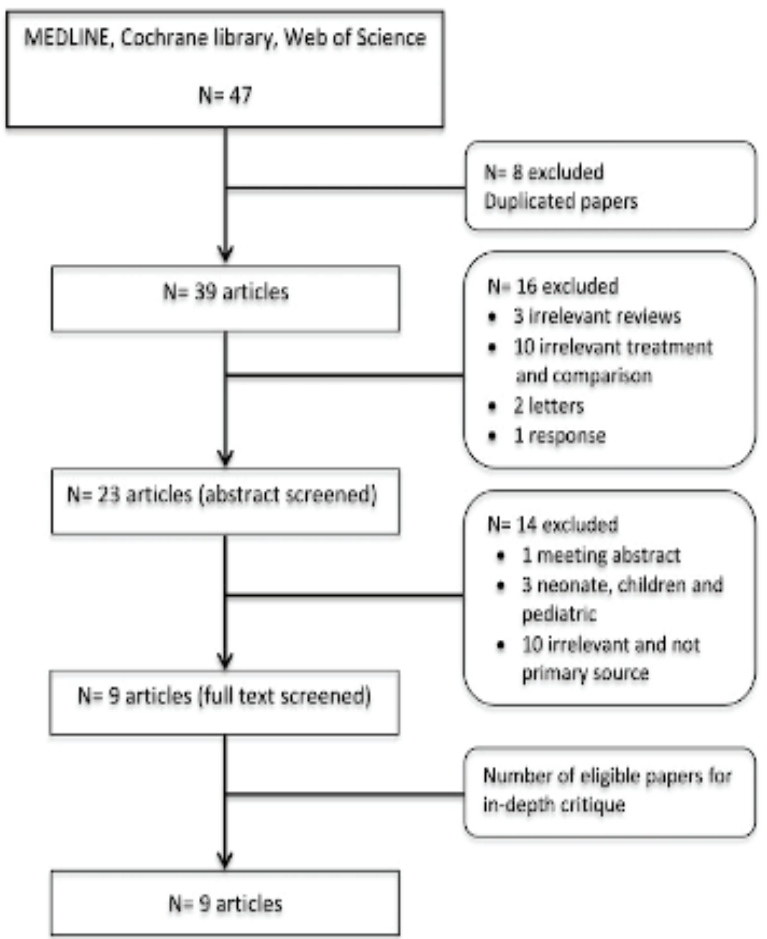

Figure 1 - Audit trial of the screening and selecting the eligible papers.

and irrelevant papers. An audit trial diagram is included in Figure 1. Table 2 summarizes the papers selected for this critical review.

Discussion. This article discusses the different types of interfaces that can be used with hospitalized patients, risk factors for facial pressure ulcers development and the strategies for prevention and management of these injuries, the impact of interface type on pressure injury development and the effect of prophylactic facial dressing in the prevention of facial pressure injuries. In addition, this review discusses the use of humidification with NIV and its potential role in the development of pressure injuries. 
Table 2 - The selected papers for the critical review.

\begin{tabular}{|c|c|c|c|}
\hline The selected papers & Design & Study population & The study objective \\
\hline Gregoretti et $\mathrm{al}^{31}$ & RCT & $\begin{array}{l}47 \text { patients with ARF of different } \\
\text { etiologies. }\end{array}$ & $\begin{array}{l}\text { To evaluate patient comfort, skin breakdown and eye irritation when } \\
\text { comparing a prototype face mask (PM) and conventional face masks } \\
(\mathrm{CMs}) \text { during non-invasive ventilation. }\end{array}$ \\
\hline Lemyze et $\mathrm{al}^{40}$ & $\begin{array}{l}\text { Prospective } \\
\text { observational study }\end{array}$ & $\begin{array}{l}74 \text { patients with a do-not- } \\
\text { intubate order and treated by } \\
\text { NIV for ARF. }\end{array}$ & $\begin{array}{l}\text { To evaluate the impact of switching to total face mask in cases where face } \\
\text { mask-delivered noninvasive mechanical ventilation has already failed in } \\
\text { do-not-intubate patients in acute respiratory failure. }\end{array}$ \\
\hline Schallom et $\mathrm{al}^{35}$ & A before-after study & $\begin{array}{l}100 \text { patients with NIV orders in } \\
5 \text { ICUs. }\end{array}$ & $\begin{array}{l}\text { To examine the incidence, location, and stage of pressure ulcers and } \\
\text { patients' comfort with a nasal-oral mask compared with a full-face mask. }\end{array}$ \\
\hline Yamaguti et $\mathrm{al}^{44}$ & $\begin{array}{l}\text { Retrospective cross- } \\
\text { sectional study }\end{array}$ & $\begin{array}{l}\text { A total of } 375 \text { adult subjects with } \\
\text { ARF undergoing NIV or CPAP. }\end{array}$ & $\begin{array}{l}\text { To determine the frequency of skin breakdown and identify potential } \\
\text { treatment-related risk factors for its development in adults with ARF } \\
\text { undergoing NIV or CPAP. }\end{array}$ \\
\hline Racca et $\mathrm{al}^{16}$ & Case study report & $\begin{array}{l}\text { Two patients with ARF due to } \\
\text { Duchenne muscular dystrophy }\end{array}$ & To determine the effectiveness of helmet with neuromuscular disorders. \\
\hline Callaghan $\&$ Trapp $^{46}$ & RCT & 30 patients respiratory unit & $\begin{array}{c}\text { To compare the effectiveness of two dressing in preventing nasal bridge } \\
\text { pressure ulcer. }\end{array}$ \\
\hline Weng $^{47}$ & $\begin{array}{l}\text { Observational } \\
\text { cohort study }\end{array}$ & $\begin{array}{l}90 \text { participants were assigned } \\
\text { into three groups: control group, } \\
\text { tegasorb group, and tegaderm } \\
\text { group. }\end{array}$ & $\begin{array}{l}\text { To compare the efficacy of protective dressings and of using no materials } \\
\text { for pressure ulcer prevention. }\end{array}$ \\
\hline Otero et $\mathrm{al}^{48}$ & RCT & $\begin{array}{l}152 \text { hospitalized patients with } \\
\text { ARF and received NIV }\end{array}$ & $\begin{array}{l}\text { To comparatively assess the efficacy of four different therapeutic strategies } \\
\text { to prevent the development of facial pressure ulcers (FPUs). }\end{array}$ \\
\hline Lloys et $\mathrm{al}^{49}$ & $\mathrm{RCT}$ & 47 patients who required NIV & $\begin{array}{c}\text { To demonstrate that the use of water to seal facial mask for (NIV) reduces } \\
\text { the incidence of facial pressure ulcers. }\end{array}$ \\
\hline \multicolumn{4}{|c|}{$\begin{array}{l}\text { RCT - randomized controlled trials, NIV - noninvasive ventilation, ICU - intensive care unit, } \\
\text { CPAP - continuous positive airway pressure, ARF - acute respiratory failure }\end{array}$} \\
\hline
\end{tabular}

Table 3 - Features of an ideal noninvasive ventilation interface and securing system.

\begin{tabular}{l}
\hline Ideal noninvasive ventilation interface and securing system \\
\hline Ideal interface \\
Leak-free \\
Good stability \\
Non-traumatic \\
Light-weight \\
Long-lasting \\
Non-deformable \\
Non-allergenic material \\
Low resistance to airflow \\
Minimal dead space \\
Low cost \\
Easy to manufacture (for the moulded interfaces) \\
Available in various sizes \\
Ideal securing system \\
Stable (to avoid interface movements or dislocation) \\
Easy to put on or remove \\
Non-traumatic \\
Light and soft \\
Breathable material \\
Available in various sizes \\
Works with various interfaces \\
Washable, for home care \\
Disposable, for hospital use
\end{tabular}

Interface selection. The choice of the interface and the correct method of application have considerable impact on NIV success and the patient's tolerance of the device. In the past century, numerous interfaces of different types, materials, and styles have been developed by different companies. The variety allows the hospital staff to find the appropriate interface for each patient's needs. However, the most challenging aspect for the staff is to understand the different types of interfaces and select the most suitable option. As the interface is critical to patient comfort, NIV effectiveness, and the compliance of the patient with NIV therapy, a number of factors should be considered when selecting the interface to guarantee both patient comfort and an appropriate interface fit. ${ }^{23}$ Table 3 summarizes the features of an ideal NIV interface. ${ }^{24}$

It's preferable to use an interface with a transparent dome since it can allow visual monitoring for the presence of secretions in the oral airway. The interface should be flexible, soft and modifiable to reduce facial trauma. The interface should be rigid in its shape and non-deformable which can aid in its application on the patients face and prevent air leaks. ${ }^{23}$ 
Table 4 - Risk factors the development of interface-related pressure injuries in NIV, adapted from Brill. ${ }^{24}$

\begin{tabular}{|c|c|c|}
\hline General risk factors & Extrinsic factors & Other factors \\
\hline $\begin{array}{ll} & \text { Sensory impairment } \\
\text { - } & \text { Acute illness } \\
\text { - } & \text { Chronic illness } \\
\text { - } & \text { Expoxia or very low blood pressure } \\
\text { - } & \text { Low level of consciousness } \\
\text { - } & \text { Psychological status } \\
\text { - } & \text { Malnutritition/dehydration } \\
\text { - } & \text { Chronic skin condition } \\
\text { - } & \text { History of previous pressure damage } \\
& \text { Medication (e.g. analgesia, chronic steroid } \\
& \text { therapy, cytotoxins) }\end{array}$ & $\begin{array}{l}\text { - } \quad \text { Closely fitting headgear and } \\
\text { over-tightened straps } \\
\text { Poorly fitted masks and headgear } \\
\text { (i.e. too big or too small, too old } \\
\text { or wrong style) } \\
\text { Mechanical forces: pressure, } \\
\text { shear or friction from the } \\
\text { interface } \\
\text { - Allergy to the cushion }\end{array}$ & $\begin{array}{l}\text { - Skin damage: dry, flaky, } \\
\text { excoriated, discoloured } \\
\text { or macerated skin } \\
\text { - } \quad \text { edema } \\
\text { Shape and size of nose/ } \\
\text { face } \\
\text { Time period that mask } \\
\text { - } \quad \text { pressure is applied } \\
\text { Inability to self-manage } \\
\text { the mask }\end{array}$ \\
\hline
\end{tabular}

The choice of interface is generally influenced by patient characteristics including facial anatomy, level of comfort, and breathing pattern. However, there are additional important factors that can affect the clinical effectiveness of the interface, such as staff experience, the availability of the interface, and economical considerations..$^{24}$ The literature indicates that there are 6 primary types of interface available in different sizes, including mouthpiece, nasal mask, nasal pillow, oronasal mask, total face mask (TFM), and helmet interfaces. ${ }^{23}$ Clinically, the oronasal mask is most often used for the initial treatment of ARF. This was reflected in a large web-based survey of North America and Europe. Other commonly used types are, in descending order, TFM, nasal mask, and helmet. ${ }^{25}$

The oronasal interface is widely used in ICUs, as patients with ARF are often mouth breathers with high respiratory demands. This interface covers both the nose and mouth of the patient, which enables better elimination of high $\mathrm{CO}_{2}$ levels and decreases the nasal resistance that can develop with nasal mask use. $^{26} \mathrm{~A}$ TFM is an alternative to the oronasal mask; it contacts the perimeter of the face and thus does not apply direct pressure to the bony prominence areas. It is recommended for use only in ICUs under close monitoring, as patients may experience vomiting and aspiration, resulting in pneumonia. This mask has an anti-asphyxia valve that opens in case of malfunction: when the positive pressure decreases below $3 \mathrm{~cm} \mathrm{H}_{2} \mathrm{O} .{ }^{23}$ However, the oronasal and TFM are coming with same disadvantages. They are associated with difficultly in speaking, eating and drinking, expectoration for secretions when mask is not removed, risk of aspiration, irritation to eyes, mouth dryness, nasal congestion and claustrophobia feelings in some patients..$^{27,28}$

The nasal mask is the most-often used interface for patients who require long-term support, as this mask covers only the nose, which is more comfortable and allows the patient to communicate. ${ }^{18}$ However, its efficacy depends on the patient keeping the mouth closed. The use of chin straps can help prevent leaks from the mouth. An alternative to the nasal mask is the nasal prong, which has soft rubber or silicone pledgets that insert directly into the nares. It can be beneficial if the patient develops pressure ulcers, since the nasal prong applies no pressure to the nose area. ${ }^{7}$

A transparent helmet has been developed to reduce pressure ulcers due to masks, as it does not apply pressure to the facial area. ${ }^{13}$ It consists of transparent plastic material that allows the patient to observe and interact with the surrounding environment. A nasogastric tube can be inserted through this helmet for improved patient comfort and increased staff convenience. Helmet use decreases pressure ulcers, conjunctivitis, and gastric distension, but it should be used only in appropriate settings such as ICUs. ${ }^{28}$ In addition, one study showed that helmet use could result in rebreathing of $\mathrm{CO}_{2}$, so it should be used with caution. ${ }^{29}$

Risk factors for facial pressure ulcers development and their management. Regularly health care staff should fit the NIV mask to the patient's face to keep it in place and create a proper seal. Most NIV failures are caused by technical issues, such as air leaks, skin lesions, and patient intolerance. The purpose of health care staff is to provide maximum comfort to the patient by preventing mask-related side effects such as facial skin breakdown and leaks. ${ }^{18}$ Applying too much pressure to the face results in patient discomfort and pressure ulcers, which reduces tolerance to NIV and the success of the treatment. According to Carron et $\mathrm{al}^{18}{ }^{18}$ the incidence of such ulcers is between 5 and 50\% after 2 hours, and increases dramatically after 2 days of NIV mask 
use. A longer duration of NIV mask use increases the contact pressure on the nasal areas and results in skin breakdown. ${ }^{2}$ These lesions normally develop over the bridge of the nose, as there is very little subcutaneous tissue in this area. ${ }^{30,31}$ According to Munckton et al, ${ }^{30}$ factors that can aggravate the pressure damage include progressive tightening of the tension strap, increased inspiratory pressure, and increased air volume in the mask cushions.

Many other patient conditions can facilitate ulcer development (Table 4). ${ }^{24}$ However, according to the literature, the primary cause of pressure ulcers is a lack of awareness and understanding of how to check the skin, how often to disconnect the NIV device, and how to ensure an appropriate mask seal without progressively increasing the strap tension. ${ }^{32}$ There is some evidence to suggest that the early identification of patients with a high risk of development of pressure ulcers at the initiation of NIV use is vital to initiate preventive therapy and decrease ulcer incidence. ${ }^{15,33,34}$

Skin assessment should begin at the areas that directly contact the mask, and those areas should be reassessed at least once per shift. ${ }^{35}$ However, Bambi et $\mathrm{al},{ }^{33}$ argued that skin assessment should be performed every 2 to 4 hours because clinical studies showed that pressure ulcers can develop in 4 to 6 hours under a continuous load. The recent pressure ulcer prevention and treatment guidelines recommend assessment at least twice per day, but their recommendation is based on a low level of evidence. ${ }^{17}$ Skin integrity should be checked every 4 hours if NIV is to be continued. . $^{36-40}$

It is also recommended that the pressure applied to the skin be as low as possible; but it is difficult to maintain ideal strap tension and a good mask seal. According to Schettino et al, ${ }^{14}$ the pressure of the mask against the skin should be 2 to $3 \mathrm{~cm} \mathrm{H}_{2} \mathrm{O}$ more than the inspiratory pressure to prevent leaks. However, in current practice, most settings do not have the technology to measure the pressure objectively. Thus, the staff should be guided by both the patient's feedback and their own experience. According to recent British Thoracic Society (BTS) guidelines, the mask should be firm but not tight. ${ }^{41}$ Other approaches recommended to reduce the pressure of the interface on the facial skin include allowing 2 fingers' distance between the harness and the facial skin and hanging the ventilator circuit to prevent movement of the interface. ${ }^{39}$ The maximum time for continuous NIV is 11 hours. After that time, it is recommended to remove the interface and allow the skin to rest for at least 4 hours. ${ }^{35,40}$

Protecting the skin by keeping it dry and clean is necessary to prevent maceration and to minimize friction..$^{42}$ Routine repositioning of the mask, a break of 10 minutes if the patient can tolerate it, and rotation of different types of masks are crucial, especially for patients at a high risk of pressure ulcers. These strategies decrease ischemia by promoting tissue blood flow. ${ }^{43}$ However, some patients cannot tolerate even very short pauses in NIV therapy. Thus, the application of nasal pillows or a helmet can help prevent facial skin damage. It is important to consider that helmet use requires experienced staff, as it may cause skin breakdown around the neck and under the armpits. This was exemplified by a case of arm vein thrombosis due to excessive pressure of the helmet straps. ${ }^{44}$

For improved pressure redistribution on the patient's face, a TFM mask that covers a larger area of the cheeks and forehead is recommended. This was evident in a study carried out by Lemyze et $\mathrm{al},{ }^{40}$ that showed patients with painful pressure ulcers who switched to a TFM had fewer ulcers even without dressing protection.

Comparison of the development of pressure ulcers using different types of interfaces. Successful NIV implementation is heavily dependent on an appropriate interface attachment to the patient's face. The selection of a proper interface requires a comprehensive assessment of the patient, the presentation, and the ventilator type. The Royal College of Physicians recommends using the measurement included in the commercial packaging of some masks to select the correct interface. The risk of facial pressure ulcers increases when the interface is attached too firmly; the damage also causes patient discomfort and intolerance, and can lead to subsequent NIV failure if severe. ${ }^{30}$ A limited number of studies have investigated the effect of different NIV interfaces on facial skin breakdown; Table 2 shows a summary of those studies.

A multicenter RCT was conducted to compare a prototype face mask (PM) and conventional face masks (CMs) during NIV and to evaluate patient comfort, skin breakdown, and eye irritation. ${ }^{31}$ Before the study was discontinued, they showed that skin breakdown and patient comfort were significantly higher in the CMs group than the PM group ( $p<0.001$ and $p=0.003$ ). However, the trial used different ventilation settings with different ventilators types, which could affect the outcome as a confounding variable. The positive airway pressure was generated through 2 different ventilators which were turbine driven portable ventilators and intensive care unit ventilators. Therefore, skin breakdown could be attributed to that variability since the ventilator type and settings can affect the pressure that exerted on the facial area especially at the bridge of the nose. 
Another prospective observational study was conducted by Lemyze et $\mathrm{al}^{40}$ to evaluate the impact of switching to a TFM in cases where FM delivered NIV had already failed in do-not-intubate patients with ARF. Thirty-six of 74 patients were switched from a FM to a TFM because of FM failure due to $\mathrm{CO}_{2}$ retention $(\mathrm{n}=24,66.7 \%)$, pressure ulcer and discomfort $(\mathrm{n}=11$, $30 \%)$, or refractory hypoxemia $(n=1,2.7 \%)$. In patients who were switched due to pressure ulcers, they found that despite the decreased use of protective dressing and longer NIV use, an early change to a TFM (in the first 12 hours) reduced the incidence of pressure ulcers $(n=5,24 \%$ versus $n=13,87 \% ; p=0.0002)$. They also concluded that the comfort level was statistically significant $(p=0.004)$ in all patients who were switched to the TFM. In their study, approximately $72 \%$ of the patients who required $>12$ hours of FM within the first 2 days developed facial pressure sores. Therefore, they recommend that the TFM should be considered for prolonged NIV use instead of the FM for decreased skin breakdown and better patient outcomes.

The third study in this review was conducted by Schallom et $\mathrm{al}^{35}$ in $5 \mathrm{ICU}$ s and investigated pressure ulcer incidence, location, and level of comfort of oronasal mask use compared to a TFM. A total of 200 patients were equally divided into 2 groups, and each group received a different type of mask. The results agreed with Lemyze et $\mathrm{al}^{40}$ that the use of a TFM significantly reduced the incidence of pressure ulcers $(p<0.001)$ and increased the comfort level $(p<0.001)$ compared to the oronasal mask. They determined that the average time of development of a pressure ulcer was 28.4 hours for the oronasal mask and 61.37 hours for the TFM. This finding suggests that the use of a TFM as early as possible is a practical strategy to reduce ulcers and is due to its features, which enhance pressure distribution. However, these findings cannot be extrapolated to all ARF conditions as ARF patients with eye surgery or glaucoma cannot wear a TFM.

Yamaguti et $\mathrm{al}^{44}$ conducted a retrospective crosssectional study to determine the prevalence of skin breakdown and the related risk factors. As in the 2 studies discussed previously, they reported that the use of an oronasal mask for more than 26 hours and prolonged NIV use were independently related to pressure ulcer development. They enrolled 375 subjects in the study. Of those, 54 subjects developed ulcers (14.4\%). Only $13.1 \%$ has developed stage I skin breakdown and that of stage II was $1.3 \%$. Higher skin breakdown developed in 50 subjects $(92.6 \%)$ using oronasal masks compared to 4 subjects $(7.4 \%)$ using TFMs $(p>0.001)$. They recommend the use of TFMs for patients requiring
NIV and routine interface rotation and alternation for better pressure ulcer prevention.

A transparent helmet was developed to reduce the common side effects of masks, including pressure ulcers, as the helmet does not apply pressure to the facial areas. ${ }^{45} \mathrm{~A}$ case study was conducted by Racca et $\mathrm{al}^{16}$ to assess the efficiency of the helmet in patients with neuromuscular disorders. They used helmets in 2 patients with Duchenne-type muscular dystrophy (DMD) with ARF and nasal ulceration instead of nasal masks. This finding, while preliminary, suggests that the use of a helmet increases NIV tolerance and allows pressure ulcers to heal. These studies indicate that, although the oronasal mask is the interface most often used for the initial treatment of ARF, it is also a strong a risk factor for the development of pressure ulcers. Therefore, initial use of the TFM is strongly suggested to reduce the development of such ulcers, as it can cover the perimeter of the face and avoid the application of direct pressure to the bony prominence areas. Routine interface rotation and alternation with other types are also suggested.

Prophylactic facial dressing in the prevention offacial pressure ulcers. According to EPUAP (2014) guidelines, the regular use of protective skin coverings such as hydrocolloids, foam pads, transparent film, silicone, and gel on areas with the highest contact pressure is an important factor in decreased facial skin breakdown and the prevention of small leaks. ${ }^{17}$ High-risk patients should use such materials either from the beginning of therapy, or once any sign of skin redness develops. It is believed that the patient's movements, sweating, and fluid status all contribute to changes in the mask seal. However, the most important thing is to routinely monitor the mask fit and the patient's skin throughout therapy and resolve any problem that occurs. A literature review revealed limited data on the association between protective dressings and the development of facial pressure ulcers. Two controlled trials compared the effect of different types of protective dressings on the development of facial pressure ulcers and reported a lower prevalence of facial pressure ulcers. In the first study, Callaghan and Trapp ${ }^{46}$ evaluated 2 different dressings for prevention of nasal pressure ulcers. A total of 30 patients were divided equally into 3 groups: Granuflex, Spenco Dermal, and a non-randomized control group. Granuflex (3 lesions) provided better protection than Spenco Dermal (7 lesions) or no dressing (9 lesions). Granuflex group had less skin deterioration over time compared to patients using Spenco Dermal 3/10 (30\%), 7/10 (70\%) respectively. In comparison with no dressing, there was a greater protective effect in the Granuflex group than 
control group 3/10 (30\%), 9/10 (90\%) correspondingly. The severity of the pressure injury was more severe in the control group than other treatment groups which demonstrate the potential benefits of temporary usage of prophylactic dressings in prevention of pressure injuries. A similar, larger comparative control trial was conducted by Weng ${ }^{47}$ to compare and determine the effectiveness of the use of a protective dressing or no dressing on facial areas. The trial included 90 participants with no previous facial pressure ulcers divided equally to 3 groups: the Tegaderm ${ }^{\mathrm{TM}}$ (hydrocolloid) group, the Tegasorb $^{\text {тм }}$ (film) group, and the control group. They found that the incidence of pressure ulcers decreased significantly in the Tegaderm and Tegasorb groups $(p<0.01)$ compared to the control group. The incidence of pressure ulcers in the control group was $96.7 \%$. The authors recommended the regular use of both Tegasorb and Tegaderm on the face, but also suggested that the application of Tegasorb is more suitable than a hydrocolloid to enable the detection of any changes in the skin, as it is transparent.

Recently, the effectiveness of 4 intervention schemes to prevent facial pressure ulcers development in critically patients was comparatively assessed by an $\mathrm{RCT}^{48}$ A total of 152 patients with acute respiratory failure were randomly divided to 4 groups, and each group received a different treatment. In the group that receiving a solution of hyperoxygenated fatty acids (HOFA), the incidence of facial pressure ulcers (FPUs) was significantly decrease compared to the other intervention strategies, direct mask $(p=0.055)$, adhesive thin dressing $(p=0.03)$, and adhesive foam dressing $(p<0.001)$. Approximately $48 \%$ of the total subjects $(n=152)$ have developed 87 FPUs and the nasal bridge was the most frequently anatomical area affected $(n=72)$. In patients with HOFA, only category 1 pressure ulcer developed on the nasal bridge with no development of pressure ulcers on the cheekbone. These results suggest that HOFA should be used frequently when an oronasal mask is in place, as it can protect the integrity of the facial skin. An RCT was conducted by Lloys et $\mathrm{al}^{49}$ to determine the effectiveness of water to seal an NIV facial mask and reduce the incidence of pressure ulcers. The study included 47 patients who required NIV. There were 2 patients only in the water group and 23 in the air group. Pressure ulcers developed in $39 \%$ of the patients in the air group and $25 \%$ in the water group. The usage of water delays the occurrence of facial pressure ulcers with mean time of 847 minutes.

The results of these studies indicate that the regular use of protective coverings such as hydrocolloids, transparent film, and silicone on skin subjected to high contact pressure is crucial to decrease facial skin breakdown and prevent small leaks. Such materials should be used throughout therapy by high-risk patients, or should be introduced once the patient develops any sign of skin redness.

Use of humidification with NIV. To date, according to BTS guidelines, there is no evidence to support the use of humidification in acute NIV, and it is not regularly required. ${ }^{41}$ However, Tuggey et $\mathrm{al}^{50}$ state that heated humidification reduces resistance in the upper airway and promotes patient comfort. Regular masks are made of occlusive materials such as plastic, but such materials can block normal transepidermal water loss. Over time, the increased humidity causes maceration and increased skin fragility. ${ }^{51}$ This moisture increases the effects of friction of the skin and makes it more susceptible to damage. ${ }^{37}$ According to Bates-Jensen et $\mathrm{al}^{52}$ severe pressure ulcers (Type II) are frequently associated with excessive skin moisture. Furthermore, studies concerning skin microclimate (humidity and temperature) revealed that when the skin humidity increased, skin temperature increased, and absorbency of interface decreased in skin contact the risk of superficial pressure injuries is increased. ${ }^{33,54}$ Indeed, humidification is frequently used in clinical practice although there is no strong evidence to support it. However, it can further increase skin moisture and make the skin much more vulnerable to trauma. Further studies are necessary to determine the real effect of humidification on the development of pressure ulcers. Figure 2 shows a proposed algorithm for how health care providers should approach patients on NIV so as to reduce facial pressure ulcers.

In conclusions, the development of a prevention protocol for NIV interfaces related to pressure ulcers is vital for improved NIV compliance and success. The current evidence suggests that although the oronasal mask is often the interface first used for ARF treatment, its use is a strong risk factor for the development of facial skin breakdown. Therefore, for patients who are likely to need continuous NIV over a more prolonged period of time, or those who developed any sign of facial skin injury after a regular skin evaluation, the initial use of the TFM with regular interface rotation and alternation is strongly suggested to reduce the development of such ulcers. However, in this review, no studies were found to assess the initial use of the TFM in all kinds of patients with ARF or a comparison of this approach with other preventive strategies such as facial dressings. Therefore, this result cannot be extrapolated to all patients with NIV. Regular assessments of the condition of the facial skin every 2 to 4 hours and training courses for the staff 


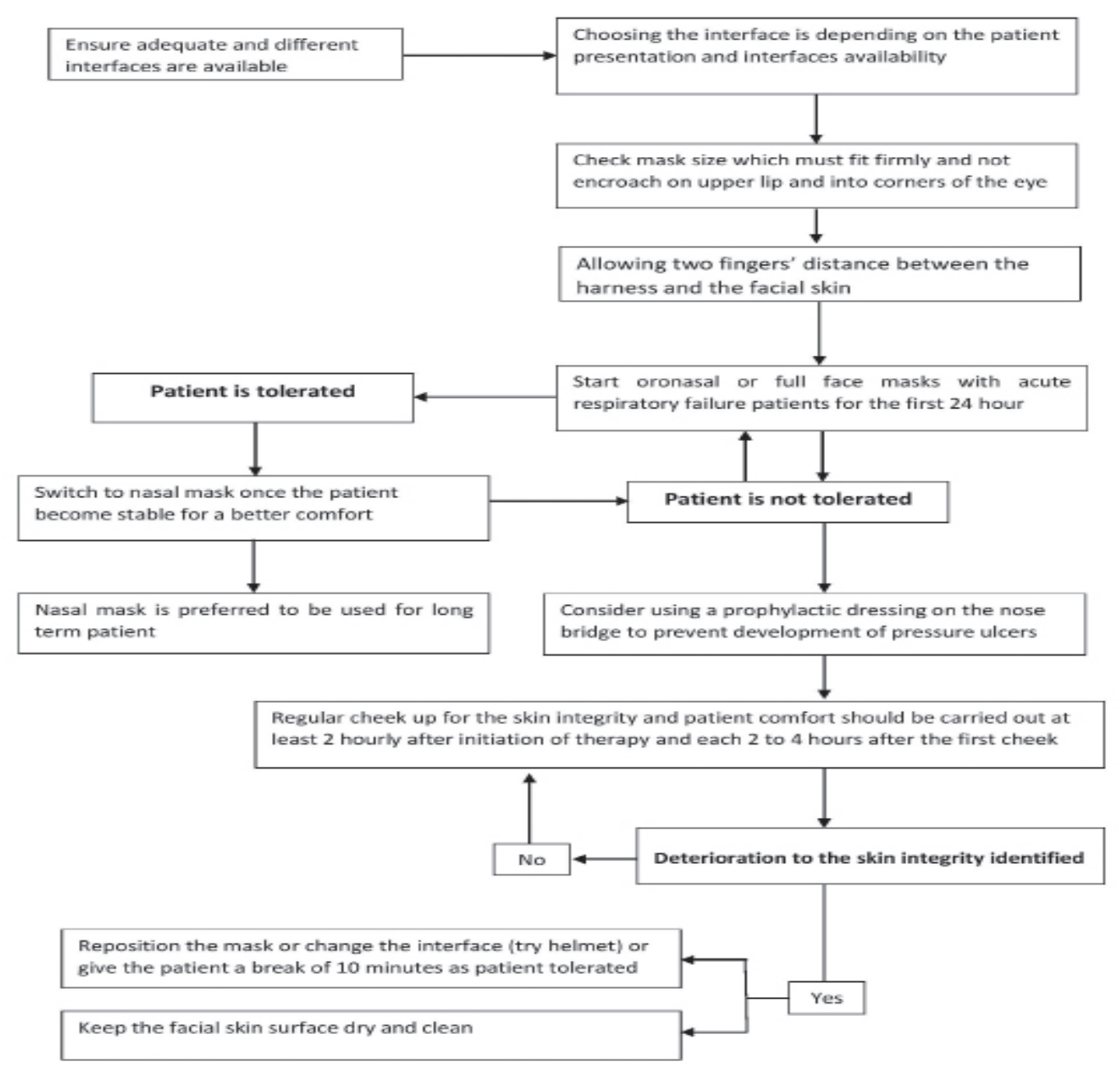

Figure 2 - Proposed algorithm for how health care providers should approach patients on NIV in order to reduce facial pressure ulcers.

are crucial to prevent and manage these skin lesions. Proper interface selection, awareness of patient-related risk factors, and accurate judgment and assessment are essential factors in the prevention of facial skin pressure ulcers. Our review has not addressed the costs of different masks and their effects and limitations to clinical utilization. In addition, the interfaces' impact on NIV efficacy was not within the scope of this review and further review is recommended to address these issues so as to have secure clinical recommendations.

\section{References}

1. Cabrini L, Idone C, Colombo S, Monti G, Bergonzi PC, Landoni $\mathrm{G}$, et al. Medical emergency team and non-invasive ventilation outside ICU for acute respiratory failure. Intensive Care Med 2009; 35: 339-343.

2. Nava $S$, Hill N. Non-invasive ventilation in acute respiratory failure. Lancet Lond Engl 2009; 374: 250-259.
3. Jois-Bilowich P, Diercks D. Emergency department stabilization of heart failure. Heart Fail Clin 2009; 5: 37- 42.

4. Plant PK, Owen JL, Elliott MW. Early use of non-invasive ventilation for acute exacerbations of chronic obstructive pulmonary disease on general respiratory wards: a multicentre randomised controlled trial. Lancet Lond Engl 2000; 355: 1931-1935.

5. Weitz G, Struck J, Zonak A, Balnus S, Perras B, Dodt C. Prehospital noninvasive pressure support ventilation for acute cardiogenic pulmonary edema. Eur J Emerg Med OffJ Eur Soc Emerg Med 2007; 14: 276-279.

6. Plaisance P, Pirracchio R, Berton C, Vicaut E, Payen D. A randomized study of out-of-hospital continuous positive airway pressure for acute cardiogenic pulmonary oedema: physiological and clinical effects. Eur Heart J 2007; 28: 2895-28901.

7. Mehta S, Hill NS. Noninvasive ventilation. Am J Respir Crit Care Med 2001; 163: 540-577.

8. Hess DR. Noninvasive positive-pressure ventilation and ventilator-associated pneumonia. Respir Care 2005; 50): 924-92. 
9. Tomii K, Seo R, Tachikawa R, Harada Y, Murase K, Kaji R, et al. Impact of noninvasive ventilation (NIV) trial for various types of acute respiratory failure in the emergency department; decreased mortality and use of the ICU. Respir Med 2009; 103: 67-73.

10. Burns KEA, Meade MO, Premji A, Adhikari NKJ. Noninvasive positive-pressure ventilation as a weaning strategy for intubated adults with respiratory failure. Cochrane Database Syst Rev 2013; (12): CD004127.

11. Schettino G, Altobelli N, Kacmarek RM. Noninvasive positivepressure ventilation in acute respiratory failure outside clinical trials: experience at the Massachusetts General Hospital. Crit Care Med 2008; 36: 441-447.

12. Thille AW, Contou D, Fragnoli C, Córdoba-Izquierdo A, Boissier F, Brun-Buisson C. Non-invasive ventilation for acute hypoxemic respiratory failure: intubation rate and risk factors. Crit Care Lond Engl 2013; 17: R269.

13. Antonelli M, Conti G, Pelosi P, Gregoretti C, Pennisi MA, Costa $\mathrm{R}$, et al. New treatment of acute hypoxemic respiratory failure: noninvasive pressure support ventilation delivered by helmet--a pilot controlled trial. Crit Care Med 2002; 30: 602-608.

14. Schettino GP, Tucci MR, Sousa R, Valente Barbas CS, Passos Amato MB, Carvalho CR. Mask mechanics and leak dynamics during noninvasive pressure support ventilation: a bench study. Intensive Care Med 2001; 27: 1887-1891.

15. Gay PC. Complications of noninvasive ventilation in acute care. Respir Care 2009; 54: 246-257.

16. Racca F, Appendini L, Berta G, Barberis L, Vittone F, Gregoretti $\mathrm{C}$, et al. Helmet ventilation for acute respiratory failure and nasal skin breakdown in neuromuscular disorders. Anesth Analg 2009; 109: 164-167.

17. National Pressure Ulcer Advisory Panel, European Pressure Ulcer Advisory Panel and Pan Pacific Pressure Injury Alliance. Prevention and treatment of pressure ulcers: Quick reference guide. Haesler E, editor. Perth (AU): Cambridge Media; 2014.

18. Carron M, Freo U, BaHammam AS, Dellweg D, Guarracino F, Cosentini R, et al. Complications of non-invasive ventilation techniques: a comprehensive qualitative review of randomized trials. Br J Anaesth 2013; 110: 896-914.

19. Posnett J, Franks PJ. The cost of skin breakdown and ulceration in the UK. In: Pownall M, editor. Skin breakdown: The Silent Epidemic. London and Hull (UK): Smith \& Nephew Foundation; 2007. p. 6-12.

20. Bennett G, Dealey C, Posnett J. The cost of pressure ulcers in the UK. Age Ageing 2004; 33: 230-235.

21. Beitz JM, Fey J, O'Brien D. Perceived need for education vs. actual knowledge of pressure ulcer care in a hospital nursing staff. Medsurg Nurs 1998; 7: 293-301.

22. Cabrini L, Esquinas A, Pasin L, Nardelli P, Frati E, Pintaudi M, et al. An international survey on non invasive ventilation used for acute respiratory failure in general non-monitored wards. Respir Care 2015; 60: 586-592.

23. Nava S, Navalesi P, Gregoretti C. Interfaces and humidification for noninvasive mechanical ventilation. Respir Care 2009; 54: 71-84.

24. Brill AK. How to avoid interface problems in acute noninvasive ventilation. Breathe 2014; 10: 230-242.

25. Crimi C, Noto A, Princi P, Esquinas A, Nava S. A European survey of noninvasive ventilation practices. Eur Respir J 2010; 36: 362-369.
26. Kwok H, McCormack J, Cece R, Houtchens J, Hill NS. Controlled trial of oronasal versus nasal mask ventilation in the treatment of acute respiratory failure. Crit Care Med 2003; 31 : 468-473.

27. Navalesi P, Fanfulla F, Frigerio P, Gregoretti C, Nava S. Physiologic evaluation of noninvasive mechanical ventilation delivered with three types of masks in patients with chronic hypercapnic respiratory failure. Crit Care Med 2000; 28: 1785-1790.

28. Girault C, Briel A, Benichou J, Hellot M-F, Dachraoui F, Tamion $\mathrm{F}$, et al. Interface strategy during noninvasive positive pressure ventilation for hypercapnic acute respiratory failure. Crit Care Med 2009; 37: 124-131.

29. Taccone P, Hess D, Caironi P, Bigatello LM. Continuous positive airway pressure delivered with a "helmet": effects on carbon dioxide rebreathing. Crit Care Med 2004; 32: 2090-2096.

30. Munckton K, Ho KM, Dobb GJ, Das-Gupta M, Webb SA. The pressure effects of facemasks during noninvasive ventilation: a volunteer study. Anaesthesia 2007; 62: 1126-1131.

31. Gregoretti C, Confalonieri M, Navalesi P, Squadrone V, Frigerio P, Beltrame F, et al. Evaluation of patient skin breakdown and comfort with a new face mask for non-invasive ventilation: a multi-center study. Intensive Care Med 2002; 28: 278-284.

32. Apold J, Rydrych D. Preventing device-related pressure ulcers: using data to guide statewide change. J Nurs Care Qual 2012; 27: 28-34.

33. Bambi S, Peris A, Esquinas AM. Pressure ulcers caused by masks during noninvasive ventilation. Am J Crit Care 2016; 25: 6-16.

34. Maruccia M, Ruggieri M, Onesti MG. Facial skin breakdown in patients with non-invasive ventilation devices: report of two cases and indications for treatment and prevention. Int Wound J 2015; 12: 451-455.

35. Schallom M, Cracchiolo L, Falker A, Foster J, Hager J, Morehouse T, et al. Pressure ulcer incidence in patients wearing nasal-oral versus full-face noninvasive ventilation masks. Am J Crit Care 2015; 24: 349-356.

36. Ahmad Z, Venus M, Kisku W, Rayatt SS. A case series of skin necrosis following use of non invasive ventilation pressure masks. Int Wound J 2013; 10: 87-90.

37. Kiss EA, Heiler M. Pediatric skin integrity practice guideline for institutional use: a quality improvement project. J Pediatr Nurs 2014; 29: 362-367.

38. Ferrario D, Lucchini A. [Helmet delivered CPAP for inpatient]. Minerva Anestesiol 2002; 68: 481-484. Italian

39. Meduri GU, Abou-Shala N, Fox RC, Jones CB, Leeper KV, Wunderink RG. Noninvasive face mask mechanical ventilation in patients with acute hypercapnic respiratory failure. Chest 1991; 100: 445-454.

40. Lemyze M, Mallat J, Nigeon O, Barrailler S, Pepy F, Gasan G, et al. Rescue therapy by switching to total face mask after failure of face mask-delivered noninvasive ventilation in do-not-intubate patients in acute respiratory failure. Crit Care Med 2013; 41 : 481-488.

41. Davidson C, Banham S, Elliott M, Kennedy D, Gelder C, Glossop A, et al. British Thoracic Society/Intensive Care Society Guideline for the ventilatory management of acute hypercapnic respiratory failure in adults. BMJ Open Respir Res 2016; 3: e000133.

42. Sivamani RK, Goodman J, Gitis NV, Maibach HI. Friction coefficient of skin in real-time. Skin Res Technol 2003; 9: 235-239. 
43. DeGiorgi A, White M. Noninvasive ventilation: principles and pitfalls. Emerg Med 2008; 40: 10-14.

44. Yamaguti WP, Moderno EV, Yamashita SY, Gomes TG, Maida ALV, Kondo CS, et al. Treatment-related risk factors for development of skin breakdown in subjects with acute respiratory failure undergoing noninvasive ventilation or CPAP. Respir Care 2014; 59: 1530-1536.

45. Antonelli M, Conti G, Pelosi P, Gregoretti C, Pennisi MA, Costa $\mathrm{R}$, et al. New treatment of acute hypoxemic respiratory failure: noninvasive pressure support ventilation delivered by helmet. A pilot controlled trial. Crit Care Med 2002; 30: 602-608.

46. Callaghan S, Trapp M. Evaluating two dressings for the prevention of nasal bridge pressure sores. Prof Nurse Lond Engl 1998; 13: 361-364.

47. Weng $\mathrm{MH}$. The effect of protective treatment in reducing pressure ulcers for non-invasive ventilation patients. Intensive Crit Care Nurs 2008; 24: 295-299.

48. Otero DP, Domínguez DV, Fernández LH, Magariño AS, González VJ, Klepzing JG, et al. Preventing facial pressure ulcers in patients under non-invasive mechanical ventilation: a randomised control trial. J Wound Care 2017; 26: 128-136.
49. Lloys A, Madrid C, Solà M, Segura M, Tarrés E, Mas A. The use of water to seal facial mask for non invasive ventilation reduces the incidence of pressure ulcers. Enferm Intensiva 2003; 14 : 3-6.

50. Tuggey JM, Delmastro M, Elliott MW. The effect of mouth leak and humidification during nasal non-invasive ventilation. Respir Med 2007; 101: 1874-1879.

51. Visscher MO, White CC, Jones JM, Cahill T, Jones DC, Pan BS. Face Masks for Noninvasive Ventilation: Fit, Excess Skin Hydration, and Pressure Ulcers. Respir Care 2015; 60: 1536-1547.

52. Bates-Jensen BM, McCreath HE, Pongquan V. Subepidermal moisture is associated with early pressure ulcer damage in nursing home residents with dark skin tones: pilot findings. $J$ Wound Ostomy Continence Nurs 2009; 36: 277-284.

53. Yusuf S, Okuwa M, Shigeta Y, Dai M, Iuchi T, Rahman S, et al. Microclimate and development of pressure ulcers and superficial skin changes. Int Wound J 2015; 12: 40-46.

54. Gefen A. How do microclimate factors affect the risk for superficial pressure ulcers: a mathematical modeling study. $J$ Tissue Viability 2011; 20: 81-88. 